\title{
HEDGE ACCOUNTING: INTERNATIONAL FINANCIAL REPORTING STANDARDS E NORMAS DO BANCO CENTRAL DO BRASIL
}

\author{
Hedge Accounting: International Financial Reporting Standards and \\ Standards of the Central Bank of Brazil
}

Sérgio de ludícibus

E-mail: siudicibus@osite.com.br

Doutor em Controladoria e Contabilidade pela Universidade de São Paulo; Professor Emérito na Universidade de São Paulo; Professor na Pontifícia Universidade Católica de São Paulo. http://orcid.org/0000-0001-9657-7186

Ana Paula Correia Lacanna

E-mail: profanapaula_lacanna@hotmail.com

Mestre em Ciências Contábeis e Atuariais pela Pontifícia Universidade Católica de São Paulo; Professora no Curso de Ciências Contábeis do Centro Universitário Assunção. http://orcid.org/0000-0002-8622-0607

José Everardo Alves Pereira

E-mail: joseeverardo2011@hotmail.com

Mestre em Ciências Contábeis e Atuariais pela Pontifícia Universidade Católica de São Paulo; Professor de Finanças Corporativas na Faculdade FECAF.

http://orcid.org/0000-0003-1526-1062

Ilse Maria Beuren

E-mail: ilse.beuren@gmail.com

Doutora em Controladoria e Contabilidade pela Universidade de São Paulo; Mestre em Ciências Contábeis pela Fundação Getúlio Vargas; Mestre em Administração pela Universidade Federal do Rio Grande do Sul; Professora no Programa de Pós-Graduação em Contabilidade da Universidade

Federal de Santa Catarina.

Endereço para contato: Rua Eng. Agronômico Andrei Cristian Ferreira, s/n, Trindade, 88040-900,

Florianópolis, Santa Catarina, Brasil. http://orcid.org/0000-0003-4007-6408

Artigo recebido em 25 de janeiro de 2020. Aceito em 17 de agosto de 2020. 


\section{Resumo}

Em 2008 foi anunciada a revisão do International Accounting Standard (IAS 39), segmentada em três etapas principais, a classificação e mensuração dos instrumentos financeiros, a introdução de uma nova metodologia para o cálculo de perda incorrida (impairment) e hedge accounting. Esse projeto resultou na publicação, em julho de 2014, da nova norma dos Instrumentos Financeiros, o IFRS 9. O objetivo deste estudo foi analisar os principais impactos trazidos pelo IFRS 9, frente aos normativos contábeis do Plano Contábil das Instituições do Sistema Financeiro Nacional (Cosif), no que tange à contabilização de hedge accounting. Realizou-se uma análise comparativa dos normativos locais e internacionais e, de modo complementar, analisou-se o impacto da aplicação dos padrões contábeis internacionais nas demonstrações contábeis brasileiras em Generally Accepted Accounting Principles do Banco Société Générale do Brasil, com data-base de 30 de junho de 2017. Os resultados da pesquisa mostram que, com as alterações trazidas pelo IFRS 9, maior detalhamento das informações sobre o hedge accounting passou a ser exigido, o que impacta consideravelmente o conteúdo e o formato atual das notas explicativas. A análise das notas explicativas da instituição financeira revelou a necessidade de adequação quanto à forma de divulgação dos itens designados como instrumentos de hedge, separados por categoria de risco, e quanto ao formato requerido, apresentar um nível de detalhamento dos valores por categoria de risco para os tipos de hedge. Nesse sentido, o estudo tem como principal contribuição a demonstração de que os requerimentos locais das divulgações dos instrumentos financeiros precisam de adequações.

Palavras-chave: Hedge Accounting. IAS 39. IFRS 9. COSIF.

\section{Abstract}

In 2008 it was announced the revision of International Accounting Standard (IAS 39), segmented into three main stages, the classification and measurement of financial instruments, the introduction of a new methodology for the calculation of impairment and hedge accounting. This project resulted in the publication in July 2014 of the new Standard of Financial Instruments, IFRS 9. The objective of this study was to analyze the main impacts brought by IFRS 9, in comparison with accounting standards in the Accounting Plan of National Financial System Institutions (COSIF), in relation to accounting for hedge accounting. A comparative analysis of local and international regulations was carried out and, in a complementary manner, was analyzed the impact of the application of international accounting standards on Brazilian accounting statements in Generally Accepted Accounting Principles of Banco Société Générale do Brazil, basis of June 30 2017. The results of the research show that, with the changes introduced by IFRS 9, more detailed information on hedge accounting has been required, which considerably impacts the content and the current format of the explanatory notes. The analysis of the financial institution's explanatory notes revealed the need for adequacy as to the way of discloser the items designated as hedge instruments, separately by risk category, and as to the required format, present a level of detail of the values by risk category for types of hedge. In this sense, the study's main contribution is to demonstrate that the local requirements of the disclosures of financial instruments need adjustments.

Keywords: Hedge Accounting. IAS 39. IFRS 9. COSIF. 


\section{INTRODUÇÃO}

A implementação das regras para o reconhecimento, a mensuração e a divulgação do hedge accounting no cenário internacional é marcada pela edição do IAS 39 - Instrumentos Financeiros, pelo International Accounting Standards Board (IASB). No segmento das instituições financeiras brasileiras, parte dos requerimentos do IAS 39 foi aplicada a partir de 2002, quando o Banco Central do Brasil (Bacen) editou as Circulares n ${ }^{\circ} 3.068$, de 8 de novembro de 2001 (Bacen, 2001), $n^{\circ} 3.082$, de 30 de janeiro de 2002, e $n^{\circ} 3.086$, de 15 de fevereiro de 2002 (Bacen, 2002a, 2002b).

De modo geral, as normas emanadas pelo Bacen aplicáveis ao hedge accounting estão alinhadas às normas internacionais, pois foram baseadas no IAS 39 porém, apresentam uma série de lacunas em discussão, a serem preenchidas com a incorporação do IFRS 9. No âmbito financeiro local, a regulamentação sobre o tema figura nas Circulares Bacen $n^{\circ} 3.082$, de 30 de janeiro de 2002 (Bacen, 2002a), n 3.129, de 27 de junho de 2002 (Bacen, 2002b), e $n^{\circ} 3.150$, de 11 de setembro de 2002, e na Carta-Circular $n^{\circ} 3.023$, de 11 de junho de 2002 (Bacen, 2002c).

Dada a complexidade de interpretação e da adoção do IAS 39 no processo de convergência, após a crise de 2008, foi percebida a necessidade de realizar a revisão da norma pelos órgãos reguladores, conforme Comunicado Bacen $n^{\circ} 14.259$, de 10 de março de 2006 (Bacen, 2006), e $n^{\circ}$ 16.669, de 20 de março de 2008 (Bacen, 2008). Assim, foi criado um projeto que segmentou esse trabalho de revisão da norma em três etapas principais: (i) classificação e mensuração dos instrumentos financeiros; (ii) introdução de um modelo novo de cálculo de perda incorrida; e (iii) contabilização de hedge (KPMG, 2016). Esse projeto resultou na publicação, em julho de 2014, da nova norma dos Instrumentos Financeiros, - IFRS 9, com adoção obrigatória a partir de $1^{\circ}$ de janeiro de 2018 , sendo autorizada a aplicação antecipada (Singh, 2017).

O IFRS 9 veio preencher as lacunas anteriormente identificadas no IAS 39, frente aos normativos locais financeiros apresentados anteriormente, quanto à contabilização de hedge accounting. O IFRS 9 traz diferenças fundamentais quando comparado com o IAS 39, dentre elas: (i) requisitos simplificados para análise quantitativa e maior alinhamento com as atividades de gestão de risco da entidade; (ii) capacidade de cobertura para componentes de risco de itens não financeiros (por exemplo, maior cobertura de commodities ou outras exposições a riscos); e (iii) flexibilidade de cobertura de risco para grupos de riscos, ou seja, posições líquidas (PriceWaterhouseCoopers Brasil [PWC], 2017).

No sentido da convergência da regulação contábil aplicável ao Sistema Financeiro Nacional (SFN), o BCB tem empreendido esforços com vistas à redução de assimetrias entre o padrão contábil estabelecido no Plano Contábil das Instituições Financeiras (Cosif) e as 
melhores práticas reconhecidas internacionalmente. Como parte do processo de convergência, - Bacen estruturou um projeto denominado Agenda BC+ (2017), que tem como objetivo a definição de uma agenda de trabalho sobre questões estruturais do Bacen e do SFN, composta de quatro pilares temáticos: (i) mais cidadania financeira; (ii) SFN mais eficiente; (iii) legislação mais moderna; e (iv) crédito mais barato.

Em seu segundo pilar, SFN mais eficiente, o Bacen incluiu a atividade de revisão da contabilidade de instrumentos financeiros como um processo de convergência internacional à luz do IFRS 9. Dessa forma, o Bacen busca promover o aumento da transparência, da qualidade e da comparabilidade das demonstrações financeiras das instituições por eles reguladas, além da redução do custo de observância para as entidades reguladas.

Em razão da extensão do tema, o Bacen segregou em etapas a incorporação do padrão internacional relativo aos instrumentos financeiros. A primeira abarca os critérios de classificação, mensuração, reconhecimento e baixa de instrumentos financeiros, que foi tema do Edital de Consulta Pública n 54/2017, divulgado pelo Bacen em 30 de agosto de 2017 (Bacen, 2017). Os demais temas, relativos à provisão para perdas associadas ao risco de crédito de instrumentos financeiros, contabilidade de hedge accounting, apresentação e evidenciação de instrumentos financeiros, serão objeto de etapas posteriores.

Compreender as regras contábeis do Cosif para as operações de hedge realizadas no mercado derivativo, regras essas advindas do processo de convergência ao padrão internacional de contabilidade do IASB, em específico as normas IAS 39, IFRS 9 e IFRS 7 (International Financial Accounting Standards [IASB], 2003, 2017a, 2017b), mostra-se relevante, na medida em que esse propósito está associado à preocupação com o aumento da transparência, da qualidade e da comparabilidade das demonstrações financeiras das instituições reguladas pelo Bacen. Essa preocupação está profundamente implicada com interesses de agentes envolvidos em operações de hedge e de pesquisadores voltados à investigação da qualidade da informação contábil divulgada aos stakeholders.

Com base no exposto e na preocupação relacionada ao preparo dos Bancos, no Brasil, para a convergência e os novos requisitos do IFRS a partir de janeiro de 2018, busca-se responder a seguinte questão de pesquisa: quais as principais diferenças entre os requisitos das regras contábeis do COSIF e o padrão internacional emitido pelo IASB no que tange à contabilização e à evidenciação de hedge accounting? Assim, o objetivo deste estudo é analisar os principais impactos trazidos pelo IFRS 9, frente aos normativos contábeis do COSIF, no que tange à contabilização e à evidenciação de hedge accounting. De modo complementar, analisa-se o impacto da aplicação dos padrões contábeis internacionais nas demonstrações contábeis brasileiras em Generally Accepted Accounting Principles do Banco Société Générale do Brasil, com data-base de 30 de junho de 2017. Para análise das exigências quanto ao disclosure das informações de hedge accounting nas notas explicativas, utilizou-se o IFRS 7, adaptado e atualizado com base no IFRS 9 em novembro de 2013. 
O IFRS 9 foi aguardado pela comunidade internacional contábil por se tratar da principal fonte de orientação para a contabilização de hedge accounting. Esta pesquisa possui como base fundamental a análise de uma norma contábil internacional, o IFRS 9, emitida em julho de 2014. Os bancos que seguem as normas internacionais foram obrigados a colocá-las em prática a partir de $1^{\circ}$ de janeiro de 2018 , contudo foi permitida a adoção antecipada. Desse modo, a pesquisa limitou-se a analisar a norma em si, e não o seu produto final, além de elucidar o impacto das alterações introduzidas pelo IFRS nas demonstrações financeiras do Banco Société Générale do Brasil.

Segundo Saito e Fukui (2016), "para entender completamente o significado teórico e prático do hedge accounting, devemos ampliar nossa perspectiva para além do alcance de um argumento usual orientado a medições na literatura contábil (p. 2). A relevância do estudo está no fato de o setor financeiro representar um segmento econômico importante e por ser o mais impactado com as alterações trazidas pelo IFRS 9 no que se refere aos critérios de contabilização de hedge accounting. Também, pelos saldos representativos de instrumentos financeiros que possui. De acordo com o ranking dos 50 maiores bancos e o consolidado do Sistema Financeiro Nacional, divulgado pelo Bacen (2015), a carteira de títulos e valores mobiliários (TVM) e de instrumento financeiro derivativo (IFD) representava o valor de $\mathrm{R} \$ 1,110$ trilhão sobre o valor de ativo total de $\mathrm{R} \$ 6,214$ trilhões, em 31 de dezembro de 2014.

A relevância do estudo está na discussão e compreensão das regras contábeis do Cosif para operações de hedge advindas do processo de convergência às normas IAS 39, IFRS 9 e IFRS 7, e o impacto de sua aplicação nas demonstrações financeiras das instituições reguladas pelo Bacen. Dessa maneira, os motivos citados para a realização desta pesquisa instigam estudos futuros que averiguem quão relevantes serão os efeitos dos requerimentos do IFRS 9 quando da incorporação ao Cosif pelo Bacen, no que diz respeito à contabilização das operações de hedge accounting, e do IFRS 7, quanto ao nível de disclosure requerido durante a elaboração das notas explicativas.

\section{REVISÃO DA LITERATURA}

Carmo et al. (2011) aduzem que a contabilidade, enquanto produto da sociedade, reflete o ambiente cultural, político, legal e econômico em que opera. Esses autores destacam que o sistema contábil adotado por um país (conjunto de normas e práticas contábeis) é um reflexo da interação de diversos fatores ambientais. Embora a literatura mundial não delimite o início dos estudos sobre Contabilidade Internacional, Niyama et al. (2005) sugerem que tenham se iniciado por volta de 1950-1960, após o término da Segunda Guerra Mundial, com o restabelecimento do comércio internacional. 
No entanto, em diversos países seu impulso ocorreu mais adiante em razão de outros eventos. No Brasil, por exemplo, por meio da Lei $n^{\circ}$ 6.385, de 27 de dezembro de 1976, foi criada a Comissão de Valores Mobiliários (CVM). Em 28 de dezembro de 2007 foi promulgada a Lei $n^{\circ} 11.638$, que altera e revoga os dispositivos da Lei $n^{\circ}$ 6.404/76 (Lei das Sociedades por Ações). Novas alterações foram realizadas através da Lei n 11.941, de 27 de maio de 2009, com vistas à convergência das normas locais para as internacionais.

De acordo com Barth et al. (2007), nos países que estabeleceram o uso obrigatório dos padrões contábeis internacionais observa-se que as empresas apresentam maior qualidade contábil. No comparativo das empresas que não aplicavam os padrões internacionais, constataram que a qualidade contábil melhorou depois que passaram a adotá-los. A convergência das normas contábeis em âmbito mundial é importante para os negócios e os empreendimentos, visto que a falta de um padrão contábil para todos os países pode levar a resultados conflitantes e refletir nas decisões dos stakeholders (Santos et al., 2011).

No presente estudo focam-se, em específico, normas de contabilização e evidenciação de operações de hedge realizadas por agentes econômicos no mercado derivativo. Segundo - IAS 39, derivativos são definidos como uma espécie de instrumento financeiro cujo valor muda em resposta às mudanças específicas em taxas de juros, preços de títulos e valores mobiliários, preços de commodities, taxas de câmbio, índices ou taxas de preços, ratings ou índices de crédito, ou outra variável similar (por vezes chamada subjacente - underlying) (Bacen, 2006b).

Bernhardt et al. (2014) explicam que diferenças nos padrões contábeis levam à mensuração periódica assíncrona de ganhos e perdas relativos aos instrumentos financeiros, que são inerentes às operações de hedge. Esses desajustes contábeis levam ao aumento da volatilidade dos lucros economicamente não justificados (Glaum \& Klöcker, 2011). Segundo Marques et al. (2020), a literatura ainda não abordou o impacto das International Financial Reporting Standards (IFRS) considerando o contexto de dupla divulgação nas instituições financeiras no Brasil.

\subsection{CONTABILIZAÇÃO DE OPERAÇÕES DE HEDGE}

As operações de hedge configuram uma importante estratégia de proteção adotada por empresas para mitigar ou evitar o risco decorrente de variações de preços e taxas em posições assumidas ou futuras com essas características (Capelletto et al., 2007). Estudos contábeis sobre derivativos abordam questões fundamentais relacionadas a esse tipo de operação, com ênfase nos desafios e nas implicações da contabilidade e da divulgação de derivativos (Campbell et al., 2019). 
De acordo com Pierce (2020), as empresas podem reduzir a volatilidade dos ganhos por meio da contabilidade de hedge, mas o seu uso impõe custos e limitações. Segundo esse autor, as empresas com ganhos mais voláteis, antes da contabilização do hedge, têm maior probabilidade de usar a contabilização de hedge. Feitosa et al. (2020) observaram em uma pesquisa realizada que a utilização de hedge accounting pelos bancos no Brasil influencia positivamente na qualidade das informações contábeis produzidas pelas empresas.

De acordo com o descrito no Manual de Normas Internacionais de Contabilidade, elaborado por Ernst \& Young e Fipecafi, em 2010, à luz do IAS 39 - Financial Instruments: Recognition and Measurement, a contabilização de hedge proporciona que o reconhecimento do lucro ou perda sobre o derivativo e o reconhecimento do item objeto de hedge ocorram de forma simultânea, devendo ser aplicados somente quando o derivativo atender a determinados critérios (Ernst \& Young \& Fipecafi, 2010). Os principais critérios a serem atendidos são:

a) identificar o tipo de hedge (valor justo, fluxo de caixa ou investimento líquido);

b) identificar o item ou transação objeto de hedge;

c) identificar a natureza do risco objeto de hedge e o respectivo período;

d) identificar o instrumento de hedge;

e) demonstrar que o hedge será altamente eficaz;

f) documentar todos os passos acima a partir do início da relação de hedge;

g) monitorar a eficiência (Ernst \& Young \& Fipecafi, 2010).

Quanto às definições envolvendo a contabilização de hedge, o item objeto de hedge pode consistir em um ativo ou um passivo reconhecido, um firme compromisso não reconhecido ou um investimento líquido em uma subsidiária estrangeira (Ernst \& Young \& Fipecafi, 2010). Contudo, não é permitido que uma carteira de ativos e passivos consista em um item objeto de hedge, pois o IAS 39 possui um princípio de não permitir que posições líquidas sejam designadas como item objeto de hedge para fins de contabilização de hedge.

Como instrumentos de hedge, pode ser utilizada uma parte (50\%) ou a totalidade do instrumento de hedge na operação de proteção, mas não é permitida a utilização de um instrumento de hedge apenas durante uma parcela de sua duração (Ernst \& Young \& Fipecafi, 2010). Um único instrumento de proteção pode ser utilizado para mais de um tipo de risco, desde que seja possível identificar cada um dos riscos protegidos, calcular a eficácia do hedge e comprovar a sua vinculação com cada risco específico (Ernst \& Young \& Fipecafi, 2010). 
Alguns desses critérios foram normatizados pelo Bacen (2007). É possível, ainda, usar dois ou mais instrumentos de hedge ou parcelas destes em uma operação de hedge, exceto quando esses instrumentos resultarem em posição lançada em uma opção, pois a perda potencial em uma opção vendida pode ser bastante superior ao ganho potencial do item protegido (IAS 39, Designação de instrumentos de cobertura, item 77).

\subsection{TIPOS DE COBERTURA DE UMA OPERAÇÃO DE HEDGE E SEU RECONHECIMENTO E MENSURAÇÃO}

O IAS 39, Contabilização de cobertura, itens 85 a 87, apresenta três tipos de cobertura de uma operação de hedge, a saber:

a) Valor justo - um hedge de valor justo é definido como hedge da exposição a variações a valor justo de: (i) um ativo ou um passivo reconhecido; (ii) um firme compromisso previamente não reconhecido para comprar ou vender um ativo a preço fixo; ou (iii) uma porção identificada desse ativo ou passivo ou firme compromisso, que seja atribuível a um determinado risco e possa afetar o lucro ou perda divulgado;

b) Fluxo de caixa - um hedge de fluxo de caixa é definido como um hedge de exposição à variabilidade no fluxo de caixa, atribuível a um determinado risco associado com um ativo ou passivo reconhecido ou uma transação altamente provável, que possa afetar o resultado;

c) Hedge de investimento líquido - o IAS 39 inclui o processo tradicional de combinar ganhos ou perdas em moeda estrangeira sobre derivativos ou passivos com a reavaliação de um investimento/participação no exterior.

Na Figura l, demonstram-se os ajustes originados da posição protegida e do in strumento de proteção, no hedge de valor justo, que são efetuados diretamente no resultado.

\begin{tabular}{|c|c|}
\hline Item objeto & Instrumento de hedge (derivativo) \\
\hline$\Downarrow$ & $\Downarrow$ \\
\hline $\begin{array}{c}\text { Impacto da mudança no valor justo reconhecido } \\
\text { no balanço }\end{array}$ & $\begin{array}{c}\text { Impacto da mudança no valor justo reconhecido } \\
\text { no balanço }\end{array}$ \\
\hline$\Downarrow$ & $\Downarrow$ \\
\hline Mudança no valor justo reconhecida no resultado & Mudança no valor justo reconhecida no resultado \\
\hline \multicolumn{2}{|c|}{$\Downarrow$} \\
\hline \multicolumn{2}{|c|}{ Ineficácia do hedge no resultado } \\
\hline
\end{tabular}


Figura 1. Esquema de contabilização de hedge de valor justo. Adaptada de "Aspectos do hedge accounting não implementados no Brasil," de L. R. Capelletto, J. L. Oliveira, e L. N. Carvalho, 2007, Revista de Administração da USP, 42(4), 511-523.

Na Figura 2, demonstra-se que a parcela efetiva do hedge (derivativo) é contabilizada no Patrimônio Líquido (PL) até que o fluxo de caixa objeto da proteção ocorra, quando os ajustes no instrumento de proteção são transferidos para o resultado.

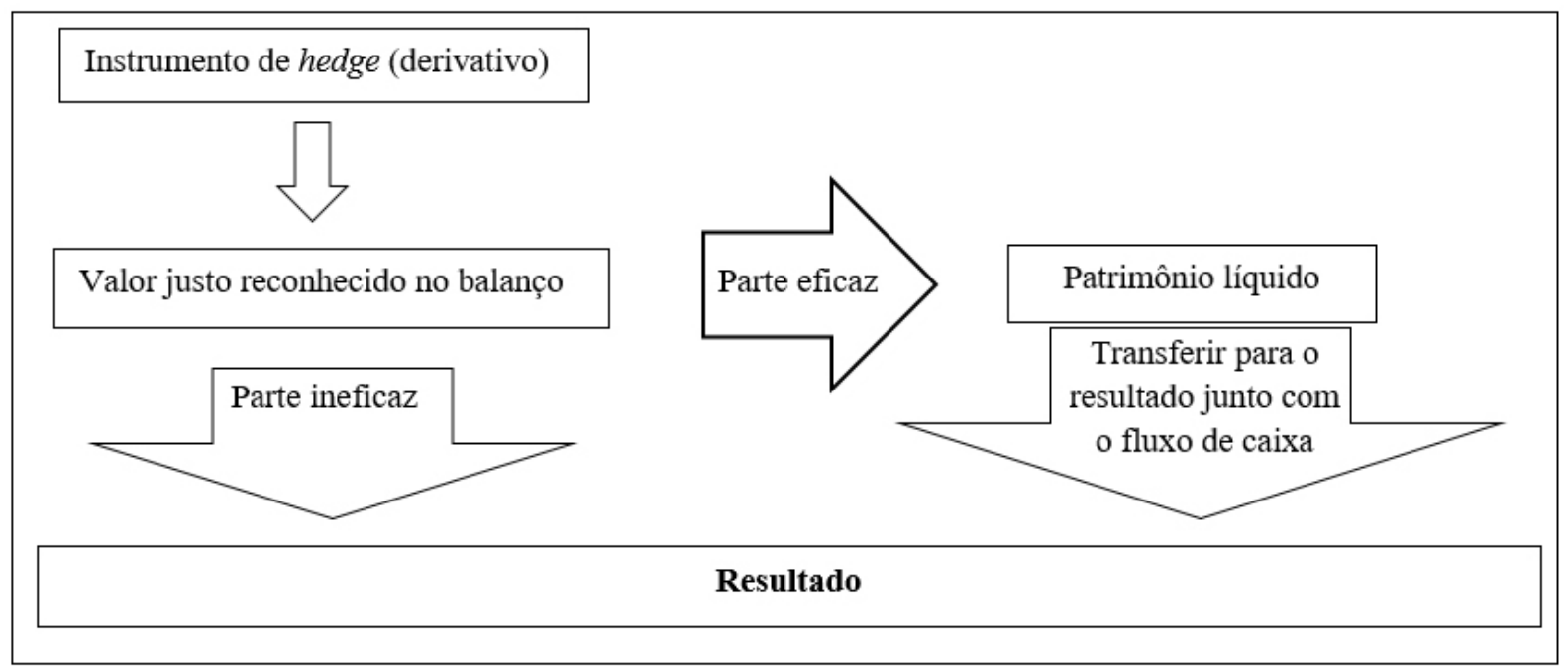

Figura 2. Esquema de contabilização de hedge de fluxo de caixa. Adaptada de "Aspectos do hedge accounting não implementados no Brasil," de L. R. Capelletto, J. L. Oliveira, e L. N. Carvalho, 2007, Revista de Administração da USP, 42(4), 511-523.

Além desses dois principais tipos de cobertura de uma operação de hedge, há o hedge de investimento líquido, que inclui, conforme o IAS 39, ganhos ou perdas em moeda estrangeira oriundos da reavaliação de participação societária no exterior.

No que tange aos resultados com o hedge, Capelletto et al. (2007) reforçam que a possibilidade de um resultado positivo ou negativo em uma operação de hedge deve tender a zero, pois o objeto intrínseco do hedge é neutralizar o risco da operação. Para fins de testes de efetividade, à luz do IAS 39, Avaliação da efetividade de cobertura, item OA105 do Apêndice A, Ernst \& Young e Fipecafi (2010) resumem da seguinte forma os dois tipos de testes de efetividade de hedge:

a) de forma prospectiva, no início e ao longo de sua vigência, cada hedge deve ser altamente efetivo, definido como o momento que as variações no valor justo ou no fluxo de caixa do item objeto de hedge compensa quase que totalmente as variações no valor justo ou no fluxo de caixa do instrumento objeto de hedge; e

b) de forma retrospectiva, mensurado a cada período, o hedge é altamente efetivo, de forma que os resultados reais se encontram na faixa de $80 \%$ a $125 \%$ (p. 304). 
Por fim, ressalta-se que o modelo contábil de macro-hedge, que corresponde aos relacionamentos de hedge dinâmicos para a carteira de ativos ou passivos, em que os montantes protegidos mudam constantemente, encontra-se em análise pelo IASB. Dessa maneira, esse modelo não será objeto de análise no presente estudo.

\section{METODOLOGIA DA PESQUISA}

A metodologia que orienta esta pesquisa é a pesquisa bibliográfica, mediante o estudo e a análise dos normativos locais e internacionais, livros e artigos que versam sobre o assunto em questão. Segundo Gil (2002), "boa parte dos estudos exploratórios pode ser definida como pesquisas bibliográficas" (p. 44). De modo complementar, analisou-se o impacto da aplicação dos padrões contábeis internacionais nas demonstrações contábeis brasileiras em Generally Accepted Accounting Principles do Banco Société Générale do Brasil, com data-base de 30 de junho de 2017.

O estudo realizado a partir das notas explicativas sobre hedge accounting das demonstrações financeiras em BRGAAP de uma instituição financeira, como complemento da pesquisa bibliográfica, teve o propósito de identificar as principais lacunas existentes entre o Cosif, o IFRS 9 e o IFRS 7, além de elucidar o conteúdo requerido na elaboração das notas explicativas à luz do que determinam o IFRS 9 e o IFRS 7. A seleção da instituição para fins de análise deu-se pelo critério de acessibilidade, e a opção pelo período considerado na análise decorre do fato de ser o imediatamente anterior às primeiras alterações oriundas da aplicação das normas convergidas aos padrões internacionais de contabilidade.

Os dados foram coletados tendo por base a análise das notas explicativas sobre hedge accounting (fluxo de caixa) apresentadas nas Demonstrações Financeiras em BRGAAP (Cosif) do Banco Société Générale do Brasil para os semestres findos em 30 de junho de 2016 e de 2017, divulgadas no site da entidade, na seção Informações aos Investidores. $\mathrm{Na}$ análise dos dados privilegiou-se a abordagem qualitativa do problema, em que se cotejou o estabelecido nos ditames legais com o que foi evidenciado nas notas explicativas pelo Banco sobre hedge accounting (fluxo de caixa). 


\section{RESULTADOS DA PESQUISA}

\subsection{ANÁLISE COMPARATIVA DOS PADRÕES CONTÁBEIS IASB E COSIF PARA HEDGE ACCOUNTING}

O IAS 39, em vigor desde $1^{\circ}$ de janeiro de 200l, foi considerado complexo pelas instituições financeiras para fins de convergência, além de não contemplar aspectos locais de operações de hedge accounting. Assim, foi proposta a revisão da norma em 2008, tendo como resultado uma nova norma de instrumentos financeiros, o IFRS 9, que estabeleceu mudanças na contabilização dos instrumentos financeiros e substituiu o IAS 39 - Instrumentos Financeiros: Reconhecimento e Mensuração. O IFRS 7, que dispõe sobre a divulgação dos instrumentos financeiros, foi emitido em agosto de 2005 pelo IASB e sofreu alterações em novembro de 2013 pelo IFRS 9 - Instrumentos Financeiros (Hedge Accounting).

O COSIF, criado em 29 de dezembro de 1987, pela Circular Bacen n 1.273, compreende - Plano Contábil das Instituições Financeiras do Sistema Financeiro Nacional e tem como objetivo unificar os procedimentos de registro e elaboração de demonstrações financeiras (Bacen, 1987). Em decorrência dos esforços empreendidos pelo BACEN, o COSIF encontra-se na iminência de ser convergido às normas internacionais de contabilidade, especificamente - IFRS 9 e o IFRS 13, no sentido de reduzir as assimetrias das normas locais com as melhores práticas contábeis reconhecidas internacionalmente.

\subsubsection{Padrões contábeis IASB para hedge accounting}

O IFRS 9 favorece o entendimento das demonstrações financeiras por parte de investidores, órgãos reguladores internacionais e agentes do mercado, além de propor mudanças na forma de apresentação das informações. Ghasmi (2016) observou que, "com o IFRS 9, há um único modelo de perda de crédito esperado progressivo aplicável a qualquer ou a todas as variedades de instrumentos monetários que estejam sujeitos a contabilidade por imparidade" (p. 31). O autor complementa que "o IFRS 9 adotou um modelo de hedge accounting melhorado, aumentando o conhecimento econômico da gestão de risco com seu tratamento contábil" (p. 31).

No entanto, há pontos do IFRS 9 em que não houve mudanças em relação ao IAS 39 e que merecem destaque. São eles: (i) os tipos de relacionamentos de hedge foram mantidos, sendo hedge de valor justo, hedge de fluxo de caixa e hedge de investimento líquido em operações no exterior; (ii) o teste de efetividade, em que as entidades ainda terão que medir a efetividade, com o uso de outros parâmetros, devendo reconhecer a não efetividade no 
resultado; (iii) quanto à documentação do relacionamento de hedge em sua designação inicial; e iv) a opcionalidade do hedge accounting, ou seja, as entidades não são obrigadas a estruturar operações de hedge. Na Tabela l, apresenta-se um resumo dessas principais diferenças dos requerimentos do hedge accounting entre as normas.

Tabela 1

Principais diferenças entre IAS 39 e IFRS 9

\begin{tabular}{|c|c|c|}
\hline Requerimento & IAS 39 & IFRS 9 \\
\hline $\begin{array}{l}\text { Qualificação do hedge } \\
\text { contábil. }\end{array}$ & $\begin{array}{l}\text { Menor quantidade de relacionamentos } \\
\text { se qualificará como hedge contábil. }\end{array}$ & $\begin{array}{l}\text { Maior quantidade de relacionamentos } \\
\text { se qualificará como hedge contábil. }\end{array}$ \\
\hline $\begin{array}{l}\text { Instrumentos de hedge } \\
\text { contábil elegíveis. }\end{array}$ & $\begin{array}{l}\text { Permite somente instrumentos finan- } \\
\text { ceiros derivativos, ativos e passivos } \\
\text { não derivativos, apenas para riscos } \\
\text { cambiais. }\end{array}$ & $\begin{array}{l}\text { Permite ativos e passivos não derivati- } \\
\text { vos mensurados a Valor Justo por meio } \\
\text { do Resultado (VJR) e componente } \\
\text { cambial (existem exceções). }\end{array}$ \\
\hline Objetos de hedge elegíveis. & $\begin{array}{l}\text { Exposições de riscos permitidas pelo } \\
\text { IAS } 39 \text { e mantidas pelo IFRS } 9 .\end{array}$ & $\begin{array}{l}\text { Novas exposições de risco introduzidas } \\
\text { pelo IFRS } 9 .\end{array}$ \\
\hline Teste $80 \%$ - $125 \%$. & $\begin{array}{l}\text { Previsão de uma faixa limite fixa de } \\
\text { efetividade. }\end{array}$ & $\begin{array}{l}\text { Não há faixa limite fixa de efetivida- } \\
\text { de. }\end{array}$ \\
\hline $\begin{array}{l}\text { Teste de efetividade quan- } \\
\text { titativo. }\end{array}$ & $\begin{array}{l}\text { Previsão de teste de efetividade quan- } \\
\text { titativo. }\end{array}$ & Depende da complexidade. \\
\hline $\begin{array}{l}\text { Teste de efetividade quali- } \\
\text { tativo. }\end{array}$ & Sem previsão. & Depende da complexidade. \\
\hline $\begin{array}{l}\text { Contabilização especial dos } \\
\text { custos de hedge. }\end{array}$ & Sem previsão. & Introduzida pelo IFRS 9. \\
\hline $\begin{array}{l}\text { Balanceamento da relação } \\
\text { de hedge. }\end{array}$ & Sem previsão. & Introduzida pelo IFRS 9. \\
\hline
\end{tabular}

De acordo com a nova norma, o IFRS 9, os critérios para qualificação são divididos em etapas:

a) instrumentos de hedge elegíveis versus itens objeto de hedge elegíveis;

b) documentação formal de designação, no momento inicial (inception), com a descrição do relacionamento de hedge, os objetivos de gerenciamento de risco e a estratégia que norteia o hedge, inclusive o índice de hedge;

c) não é requerido teste de efetividade retrospectivo;

d) relacionamento econômico entre os instrumentos de hedge e os objetos de hedge (espera-se que os seus valores se movam em direções opostas nas demonstrações financeiras) - análises contínuas desse relacionamento são necessárias;

e) o risco de crédito não deverá dominar o valor justo tanto do item objeto de hedge quanto do instrumento de hedge.

Para fins de designação dos instrumentos de hedge elegíveis, têm-se: 
a) todos os contratos de derivativos, inclusive os zero cost collars, exceto opções vendidas não designadas para compensar opções compradas e derivativos embutidos em contratos híbridos que não devem ser contabilizados separadamente;

b) contratos ativos e passivos não derivativos, mensurados como Valor Justo por meio do Resultado (VJR), exceto passivos financeiros classificados como VJR e os que apresentam as mudanças no seu valor justo, decorrentes de risco de crédito, registrados em Outros Resultados Abrangentes (ORA);

c) para hedge de risco cambial, o componente cambial de um ativo ou passivo não derivativo, exceto um instrumento de patrimônio que a entidade optou por classificar como Valor Justo por meio de Outros Resultados Abrangentes (VJORA).

O IFRS 9 permite que instrumentos ativos e passivos não derivativos sejam utilizados como instrumentos de hedge para qualquer tipo de risco, e não somente para riscos cambiais, como era previsto no IAS 39, desde que classificados como VJR. O IFRS 9 determina que, para ser elegível como um item objeto de hedge, o risco que será protegido deverá ser: (i) separadamente identificado; (ii) mensurado confiavelmente; e (iii) contratualmente especificado ou não. Os instrumentos de patrimônio classificados como Valor Justo por meio de Outros Resultados Abrangentes (VJORA) são elegíveis como objeto de hedge. Na Tabela 2, evidenciam-se as exposições ao risco já permitidas no IAS 39 e mantidas no IFRS 9, além das exposições ao risco introduzidas pelo IFRS 9.

Tabela 2

Objetos de hedge elegíveis

\begin{tabular}{ll}
\hline $\begin{array}{l}\text { Exposições ao risco já permitidas no IAS 39 e manti- } \\
\text { das no IFRS } 9\end{array}$ & Exposições ao risco introduzidas pelo IFRS 9 \\
\hline Ativos / Passivos financeiros & Ativos / Passivos não financeiros \\
\hline Taxa de juros & . Outros riscos \\
\hline Taxa de juros livre de risco (benchmark) & . Inflação não especificada contratualmente \\
\hline Mercado & Posições líquidas e camadas de componentes \\
\hline Crédito & \\
\hline Variação cambial & Exposições agregadas (não derivativos + derivativos) \\
\hline Ativos / Passivos não financeiros & \\
\hline Variação cambial &
\end{tabular}

O IAS 39 só permitia que riscos cambiais contidos em instrumentos não financeiros fossem elegíveis como objetos de hedge. O IFRS 9 introduziu a possibilidade de novos riscos serem elegíveis, como: (i) preços de commodities agrícolas e pecuárias; (ii) preços de energia; (iii) preços futuros de fretes agrícolas; e (iv) preços de commodities minerais. $O$ 
IFRS 9 determina que, de modo geral, a não ser que o risco de inflação seja contratualmente especificado, ele não é elegível como item objeto de hedge.

De acordo com o IFRS 9, dos tipos de componentes, dois valores nominais podem ser designados como item objeto de hedge: (i) um componente, que é uma proporção de todo o item; (ii) a camada de um componente, que é especificada como uma população definida, mas aberta, ou um valor nominal definido. No IFRS 9, um grupo de itens (tanto posições brutas quanto líquidas), para ser um item objeto de hedge para fins de valor justo e fluxo de caixa, terá que atender a condições: (i) a posição deve ser composta por itens, incluindo componentes de itens, que seriam individualmente elegíveis como itens objeto de hedge; e (ii) os itens no grupo devem ser gerenciáveis juntos como um grupo para fins de gerenciamento de risco.

Para os hedges de fluxo de caixa, a posição líquida é elegível somente se for um hedge de risco de variação cambial e a designação especificar o período no qual as transações previstas deverão afetar o resultado, sua natureza e volume. O IFRS 9 permite a designação de instrumentos de patrimônio que a entidade optou por classificar como VJORA como itens objeto de hedge, para um relacionamento de hedge de valor justo (KPMG, 2017).

Quanto ao teste de efetividade, diferentemente do IAS 39, o IFRS 9 não exige mais a faixa limite fixa de $80 \%-125 \%$ de efetividade. Quanto ao balanceamento, um relacionamento de hedge pode, subsequentemente, deixar de atender aos requerimentos de efetividade do hedge por conta do índice de hedge em que ele foi designado. Sobre divulgações dos instrumentos financeiros, em 2013, o IFRS 7 incorporou as mudanças no que tange à necessidade de uma divulgação mais completa, clara e precisa da estratégia de gerenciamento de risco utilizada com as operações de hedge accounting.

\subsubsection{Padrões contábeis Cosif para hedge accounting}

O Departamento de Normas e Organização do Sistema Financeiro do Bacen, em dezembro de 2006, emitiu um Relatório de Diagnóstico da Convergência às Normas Internacionais ao IAS 39, com foco no hedge accounting. Esse relatório menciona que, de modo geral, as normas emanadas pelo Bacen aplicáveis às operações de hedge accounting se encontram alinhadas às normas internacionais, mesmo porque foram baseadas no IAS 39. Contudo, as normas se apresentam mais restritivas, pois definem que só os instrumentos financeiros derivativos podem ser utilizados em operações de hedge. A norma local faz uso da expressão valor de mercado como referência para instrumentos financeiros derivativos, em detrimento da terminologia valor justo, presente no IAS 39 (IASB, 2003).

Um ponto a destacar é que a norma local, ao contrário da norma internacional, permite que um derivativo utilizado em uma operação de hedge não seja marcado a mercado nas 
seguintes situações: (i) quando estiver vinculado a uma operação de captação ou aplicação, observadas as condições definidas na Circular Bacen n 3.150, de 11 de setembro de 2002; (ii) quando for utilizado para a proteção de um título classificado na categoria mantido até o vencimento, conforme a Circular Bacen $n^{\circ}$ 3.129, de 27 de junho de 2002. Tais procedimentos ferem um requisito básico das normas internacionais, de que a única informação válida, para fins de registro de um instrumento derivativo, é seu valor justo.

Outro item pouco difundido e não reconhecido adequadamente pelas normas brasileiras é o derivativo embutido. A Circular Bacen $n^{\circ} 3.082$, de 30 de janeiro de 2002, prevê que tais derivativos devem ser registrados separadamente do contrato a que estejam vinculados, sem, contudo, detalhar tais situações. A possibilidade de garantir os fluxos de caixa futuros, independentemente das variações de mercado, proporcionada pelo derivativo embutido no contrato hospedeiro, pode ser classificada como um hedge de fluxo de caixa, devendo seguir as regras pertinentes.

A Circular Bacen $n^{\circ} 3.082$, de 30 de janeiro de 2002, estabelece a obrigatoriedade de divulgar:

a) os valores agrupados por ativo, indexador de referência, contraparte, local de negociação (bolsa ou balcão) e faixas de vencimento, destacados os valores de referência, de custo, de mercado e em risco da carteira;

b) os valores que deixaram de ser qualificados como hedge e o impacto no resultado, bem como aqueles transferidos do Patrimônio Líquido em decorrência do reconhecimento contábil das perdas e dos ganhos no item objeto de hedge;

c) as principais transações e compromissos futuros objeto de hedge de fluxo de caixa, destacados os prazos para o reflexo financeiro previsto;

d) o valor e o tipo de margens dadas em garantia.

Outra diferença não contemplada é a obrigatoriedade de divulgação da parcela não efetiva, além da efetiva, em cada modalidade de hedge. Oliveira (2003) constatou em sua pesquisa que "o nível de divulgação das operações de hedge pelos bancos é baixo, não sendo possível realizar uma avaliação consistente das operações com derivativos feitos com o objetivo de hedge" (p. 110). Oliveira (2003) também observou que "o principal motivo da baixa utilização dos critérios de hedge accounting pelos bancos brasileiros está na falta de critérios para o registro contábil de operações de hedge que envolva a proteção de toda a carteira, ou seja, o macro hedge" (p. 89). Além desses critérios já estabelecidos pelos pronunciamentos internacionais, existem outros em fase de estudos e que certamente serão regulamentados pelo Banco Central por meio do Projeto Agenda BC+ (2017). 


\subsection{ANÁLISE DA APLICAÇÃO DOS PADRÕES CONTÁBEIS IASB VS COSIF EM HEDGE ACCOUNTING}

Se o Bacen, por meio da Agenda BC+ (2017), incorporar as modificações comentadas relativas à contabilização e mensuração de hedge ao COSIF, a entidade em análise deverá observar tais requerimentos emanados pelo IFRS 9 e convergidos para os normativos contábeis locais. Para esse item, em específico, não foi possível analisar com maiores detalhes o cenário atual e o cenário proposto pelo IFRS 9, já que implicaria a coleta de dados e de informações adicionais, não expressos tão somente em notas explicativas.

Com relação ao conteúdo utilizado na elaboração das notas explicativas, a entidade deverá observar as disposições do IFRS 7 que versam sobre o assunto. Especificamente para esse requerimento, foi possível fazer uma análise das disposições do IFRS 9 e do IFRS 7 em comparação com o cenário considerado, baseado nas notas explicativas de 30 de junho de 2017 do Banco Société Générale do Brasil. Na análise, primeiramente se apresenta a nota explicativa e, na sequência, os requerimentos trazidos pelas normas internacionais.

\subsubsection{Nota explicativa do Banco Société Générale do Brasil - Apresentação da estrutura de hedge accounting}

A estratégia de utilização da estrutura de hedge accounting pode ser observada na nota explicativa $n^{\circ} 7$ - Títulos e Valores Mobiliários e Instrumentos Financeiros Derivativos, no item e.3. Nesta consta que

\footnotetext{
a estratégia de hedge accounting de fluxo de caixa do Banco é determinada com o objetivo de reduzir a volatilidade no resultado pela contratação de empréstimos em dólar junto à Matriz e seu hedge realizado com instrumentos financeiros derivativos no mercado local.
}

A nota explicativa menciona que "a estrutura visa mitigar os riscos devidos à variação de preços de moedas (variação cambial) e à variação das taxas de juros". A estrutura de hedge, composta pelo empréstimo - objeto de hedge e os derivativos - de instrumentos de hedge, são assim categorizadas, observadas as regras legais para a qualificação de hedge, conforme estabelecido pela Circular Bacen $n^{\circ}$ 3.082, de 30 de janeiro de 2002.

Ainda quanto às estruturas de hedge, é reportado que essas são montadas "observando a liquidez do mercado, o alinhamento das datas de vencimento dos derivativos com a dos empréstimos, alinhamento da qualidade de contratos de derivativos, face o montante de 
empréstimo, reduzindo, dessa forma, o risco de não efetividade destas estruturas". Por fim, a nota explicativa expõe que a

volatilidade gerada pela marcação a mercados dos derivativos é registrada no patrimônio líquido, sendo que a parcela não-efetiva é reclassificada para o resultado. A avaliação mensal da efetividade dessas estratégias é realizada pelo método de análise regressiva. $O$ valor de mercado dos derivativos foi apurado com base nas taxas médias divulgadas pela B3.

A entidade precisa complementar o seu disclosure com os requisitos emanados pelo IFRS 7. De acordo com essa norma, item 21A, a entidade aplicará os requisitos de divulgação dos parágrafos 21B-24F para as exposições a risco que ela protege e para as quais escolhe aplicar o hedge accounting. As divulgações de hedge accounting devem fornecer informações sobre:

a) estratégia de gerenciamento de risco de uma entidade e como ela é aplicada para gerenciar o risco;

b) como as atividades de hedge para entidade podem afetar o valor, a época e a incerteza de seus fluxos de caixa futuros; e

c) o efeito que o hedge accounting teve sobre a demonstração da posição financeira, a demonstração do resultado abrangente e a demonstração das mutações do patrimônio líquido da entidade.

Para fins de divulgação da estratégia de gerenciamento de risco, de acordo com o IFRS 7, item 22A, a entidade deverá:

explicar sua estratégia de gerenciamento de risco para cada categoria de risco de exposições a risco que decide proteger e para a qual hedge accounting é aplicada. Essa explicação permite que os usuários das demonstrações contábeis avaliem como surge cada risco, como a entidade gerencia cada risco, incluindo se a entidade protege um item em sua totalidade para todos os riscos ou protege um componente ou componentes do risco de um item e por que; e a extensão das exposições a risco que a entidade gerencia.

Os itens 22B e 22C do IFRS 7 determinam que para que sejam atendidos os requisitos do item 22A, apresentados anteriormente, a entidade deverá incluir as seguintes informações:

a) instrumentos de hedge utilizados (e como eles são utilizados) para proteger exposições a risco; 
b) como a entidade determina a relação econômica entre o item protegido e o instrumento de hedge;

c) como a entidade estabelece o índice de hedge e quais são as fontes de inefetividade de hedge;

d) quando uma entidade designar um componente de risco específico como item protegido, ela fornecerá informações quantitativas e qualitativas sobre como determinou o componente de risco que é designado como o item protegido $e$ como o componente de risco está relacionado ao item em sua totalidade.

O item 23F do IFRS 7 menciona-se que, para "hedges de fluxo de caixa, a entidade deverá divulgar uma descrição de qualquer transação prevista para a qual a hedge accounting tinha sido utilizada anteriormente, mas que não deve mais ocorrer".

A entidade deverá adequar a nota explicativa de $n^{\circ} 7$ com base nos requisitos apresentados. De acordo com o IFRS 7, item 21B, a divulgação deverá ser feita em uma única nota explicativa ou em uma seção separada em suas demonstrações financeiras, não havendo a necessidade de duplicá-las em outro lugar, desde que tais informações sejam incorporadas por referência cruzada das demonstrações financeiras com alguma outra demonstração.

\subsubsection{Nota explicativa do Banco Société Générale do Brasil - avaliação mensal da efetividade das estratégias de hedge accounting}

A entidade divulgou que a avaliação mensal da efetividade dessas estratégias é realizada pelo método de análise regressiva. De acordo com o IAS 39, item BC136, a qualificação para hedge accounting é baseada nas expectativas de efetividade futura (prospectiva) e na avaliação da efetividade real (retrospectiva). No item BC6.231, um hedge era considerado altamente efetivo se a compensação estivesse dentro da faixa de $80 \%$ - 125\%. O IAS 39 baseava-se em um teste de linha clara, orientado por contabilização e porcentagem (a faixa de $80 \%-125 \%$ ). Isso desvinculou a contabilização do gerenciamento de risco e, por conseguinte, o IABS decidiu requerer um modelo baseado em objetivos para testes de efetividade de hedge em vez de teste de linhas claras ( $80 \%-125 \%$ ).

O IFRS 9, item $6.41 \mathrm{C}$, dispõe sobre a relação de hedge. A relação de hedge atende aos seguintes requisitos de efetividade de hedge: 
a) existe uma relação econômica entre o item protegido e o instrumento de hedge;

b) o efeito de risco de crédito não influencia as mudanças no valor que resulta dessa relação econômica; $e$

c) oíndice de hedge da relação de hedge é o mesmo daquele resultante da quantidade do item protegido que a entidade efetivamente protege e a quantidade do instrumento de hedge que a entidade efetivamente utiliza para proteger essa quantidade de item protegido.

Dessa forma, para fins de teste de efetividade da estrutura de hedge accounting, não será mais necessário que a entidade ateste se a relação da marcação a mercado ou mark to market ( $M+M)$ do instrumento de hedge e do objeto de hedge se enquadra na faixa de limite fixa de $80 \%$ - $125 \%$ prevista no IAS 39. Para fins de efetividade do hedge à luz do IFRS 9, é necessário que exista um relacionamento econômico entre o objeto de hedge e o instrumento de hedge; que o risco de crédito dos derivativos não domine as mudanças de valor resultantes do relacionamento do hedge; e que o índice de hedge (hedge ratio), que reflete o relacionamento entre as quantidades do objeto de hedge e do instrumento do hedge, seja aquele usado para fins de gerenciamento de risco.

\subsubsection{Nota explicativa do Banco Société Générale do Brasil - apresentação do tipo de hedge accounting}

Os derivativos utilizados pelo Banco Société Générale do Brasil como instrumentos de hedge por indexador são representados na Tabela 3.

\begin{tabular}{|c|c|c|c|c|}
\hline & \multicolumn{2}{|c|}{2017} & \multicolumn{2}{|c|}{2016} \\
\hline & \multicolumn{2}{|c|}{ Valores de Mercado (BRL) } & \multicolumn{2}{|c|}{ Valores de Mercado (BRL) } \\
\hline & USD & CDI & USD & CDI \\
\hline Empréstimos & $(281.259)$ & - & $(277.066)$ & - \\
\hline $\begin{array}{l}\text { Contrato futuro de cupom cambial } \\
\text { (Futuro de DDI) }\end{array}$ & 278.055 & $(305.924)$ & 273.393 & $(284.293)$ \\
\hline $\begin{array}{l}\text { Contratos futuros de depósitos inter- } \\
\text { financeiros (Futuro de DI) }\end{array}$ & - & 281.784 & - & 276.527 \\
\hline $\begin{array}{l}\text { Marcação a mercado do hedge de } \\
\text { fluxo de caixa (Patrimônio Líquido) }\end{array}$ & & $(8.657)$ & & (378) \\
\hline $\begin{array}{l}\text { Imposto sobre a marcação a mercado } \\
\text { do hedge de fluxo de caixa }(45 \%)\end{array}$ & & 3.895 & & 170 \\
\hline
\end{tabular}


De acordo com o IFRS 7:24, item A, a entidade deve divulgar, em formato de tabela, os seguintes valores referentes a itens designados como instrumentos de hedge, separadamente por categoria de risco para cada tipo de hedge (de valor justo, de fluxo de caixa ou de um investimento líquido em uma operação no exterior):

a) o valor contábil dos instrumentos de hedge (ativos financeiros separadamente de passivos financeiros);

b) a rubrica da demonstração da posição financeira que inclui o instrumento de hedge;

c) a mudança no valor justo do instrumento de hedge utilizado como base para reconhecer a não efetividade de hedge do período; e

d) os valores nominais (incluindo quantidade como, por exemplo, tons ou metros cúbicos) dos instrumentos de hedge.

Desse modo, verifica-se que a entidade precisará se adequar ao IFRS 9 e ao IFRS 7 quanto à forma de divulgação dos itens designados como instrumentos de hedge, separadamente por categoria de risco para cada tipo de hedge.

\subsubsection{Nota explicativa do Banco Société Générale do Brasil - apresentação do objeto de hedge accounting}

A apresentação das características do objeto item da estrutura de hedge accounting pode ser observada na Nota Explicativa n 17 - Obrigações por Empréstimos e Repasses, conforme demonstrado na Tabela 4.

Tabela 4

Empréstimos

\begin{tabular}{lrrrr}
\hline & \multicolumn{2}{c}{2017} & 2016 \\
\cline { 2 - 5 } & Patrimonial & Resultado & Patrimonial & Resultado \\
\hline Obrigações por empréstimos no País & - & $(64)$ & - & - \\
\hline $\begin{array}{l}\text { Obrigações em moedas estrangeiras - exportação e } \\
\text { importação (a) }\end{array}$ & 939.018 & $(22.257)$ & 922.854 & 309.848 \\
\hline $\begin{array}{l}\text { Obrigações em moedas estrangeiras - outras obri- } \\
\text { gações (b) }\end{array}$ & 2.242 .264 & $(101.567)$ & 5.556 .050 & 1.264 .046 \\
\hline Obrigações por empréstimos no exterior (c) & 724.542 & $(51.741)$ & 556.593 & 136.130 \\
\hline Subtotal & 3.905 .824 & $(175.629)$ & 7.035 .497 & 1.710 .024 \\
\hline Repasses do País: & & & & \\
\hline
\end{tabular}




\begin{tabular}{lrrrrr}
\hline & \multicolumn{2}{c}{2017} & & \\
\cline { 2 - 6 } & Patrimonial & Resultado & Patrimonial & Resultado \\
\hline Finame & 9.381 & $(124)$ & 14.478 & $(175)$ \\
\hline Repasses do exterior: & & & & \\
\hline Obrigações por repasses no exterior (d) & 1.573 & $(158)$ & 4.331 & 777 \\
\hline Total & 3.916 .778 & $(175.911)$ & 7.054 .306 & 1.710 .626 \\
\hline
\end{tabular}

Do exposto, depreende-se que a entidade precisa se adequar ao IFRS 9 e ao IFRS 7 quanto à forma de divulgação da respectiva tabela, pois ela não evidencia os requisitos previstos na norma IFRS 7. De acordo com o IFRS 7, item 24A, item (b), para hedge de fluxo de caixa e hedge de investimento líquido em uma operação no exterior, uma entidade divulgará, em forma de tabela, os seguintes valores referentes aos itens protegidos separadamente por categoria de risco para os tipos de hedge:

a) as mudanças no valor justo do item protegido utilizado como base para reconhecer a não efetividade de hedge do período, ou seja, para hedge de fluxo de caixa, a mudança no valor utilizado para determinar a não efetividade de hedge reconhecida de acordo com o parágrafo 6.5.11 da IFRS 9;

b) os saldos na reserva de hedge de fluxo de caixa e na reserva de conversão de moeda estrangeira para hedges contínuos que são contabilizados de acordo com os parágrafos 6.5.11 e 6.5.13A da IFRS 9;

c) os saldos remanescentes na reserva de hedge de fluxo de caixa e na reserva de conversão de moeda estrangeira de qualquer relação de hedge para a qual o hedge accounting não é mais aplicado.

De acordo com o IFRS 7, item 24 C, alínea (b), para hedge de fluxo de caixa e hedge de um investimento líquido em uma operação no exterior, a entidade divulgará, em forma de tabela, os seguintes valores separadamente por categoria de risco para os tipos de hedge:

a) os ganhos e perdas de hedge do período do relatório que foram reconhecidos em outros resultados abrangentes (ORA);

b) a não efetividade de hedge reconhecida em lucros ou perdas;

c) a rubrica na demonstração do resultado abrangente que inclui a não efetividade de hedge reconhecida; 
d) o valor reclassificado da reserva de hedge de fluxo de caixa ou da reserva de conversão de moeda estrangeira para lucros ou perdas como um ajuste de reclassificação;

e) a rubrica na demonstração do resultado abrangente que inclui o ajuste de reclassificação; e

f) para hedge de posições líquidas, os ganhos ou perdas de hedge reconhecidos em uma rubrica separada na demonstração do resultado abrangente.

O IFRS 7, em seu item 24E, dispõe que a entidade deve fornecer uma conciliação de cada componente do patrimônio líquido e uma análise de outros resultados abrangentes de acordo com o IAS 1 .

Pela análise das notas explicativas relativas às operações de hedge accounting da instituição investigada e restrita ao período considerado, observa-se que a entidade precisará se adequar quanto ao formato requerido pelo IFRS 7, apresentando um nível de detalhamento dos valores por categoria de risco para os tipos de hedge.

\section{CONSIDERAÇÕES FINAIS}

Apesar do avanço observado nos últimos anos nos processos de reconhecimento, mensuração e divulgação de operações com instrumentos financeiros derivativos, estendendose às operações de hedge, constantes mudanças aliadas ao surgimento de novos produtos e formas de negociação desafiam estudiosos de contabilidade a oferecer soluções que contemplem critérios sólidos para o registro contábil. Entre as operações desafiadoras encontram-se as próprias ramificações das operações com derivativos, exemplificadas pelo hedge de taxa de juros para uma exposição líquida de carteiras ativas e passivas (macro hedge) e pelo hedge com utilização de derivativos embutidos.

No Brasil, mesmo com o expressivo volume de operações com derivativos reportados nas principais clearings e a busca da convergência aos critérios contábeis com os pronunciamentos internacionais, aspectos relevantes não foram implantados, como: (i) o hedge de investimentos no exterior; (ii) as especificações do hedge para variação de moeda estrangeira, existentes no Statement of Financial Accounting Standards - SFAS 133 (Financial Accounting Standards Board [FASB], 1998); e (iii) o completo tratamento para derivativos embutidos. $O$ recém-aprovado macro hedge também não está contemplado em normas brasileiras.

Denota-se que as normas brasileiras ainda apresentam diferenças consideráveis em relação aos pronunciamentos internacionais e não preveem o registro de determinados 
tipos de operações de hedge. Com as alterações trazidas pelo IFRS 9, o nível de exigência de divulgação em notas explicativas aumentou, tanto em termos quantitativos quanto em qualitativos. Diante disso, o IFRS 7, norma internacional que dispõe sobre os requerimentos das divulgações dos instrumentos financeiros, precisou se adequar ao nível de exigência das notas explicativas das operações com hedge accounting. Um maior nível de detalhamento das informações sobre o hedge accounting passou a ser exigido, o que impacta no conteúdo e no formato atuais das notas explicativas elaboradas pelas entidades.

No entanto, este estudo apresenta limitações decorrentes do delineamento da pesquisa, o que requer parcimônia quanto aos seus resultados. Os padrões contábeis estão em constante evolução, seja pelo aprofundamento dos estudos dos formuladores das normas elou em consequência de novos riscos ambientais enfrentados pelos stakeholders. Recomenda-se que futuras pesquisas investiguem a evolução dos padrões contábeis para operações com hedge accounting, seja do IASB, do COSIF, ou de ambos. Outra limitação concerne ao tipo de ativos financeiros abordados neste estudo, portanto pesquisas futuras podem ampliar esse escopo. Ressalta-se, ainda, que a análise das notas explicativas, relativas à contabilização de operações com hedge da instituição financeira, limitou-se à abordagem qualitativa, assim, futuras pesquisas podem destacar os efeitos quantitativos da aplicação dos novos padrões contábeis.

\section{REFERÊNCIAS}

Banco Central do Brasil. (1987). Circular Bacen n 1.273, de 29 de dezembro de 1987. Instituiu a adoção obrigatória do plano contábil das instituições do sistema financeiro nacional - COSIF. Brasília, DF: Bacen.

Banco Central do Brasil. (2001). Circular Bacen $n^{\circ} 3.068$, de 08 de novembro de 2001.

Estabelece critérios para registro e avaliação contábil de títulos e valores mobiliários. Brasília, DF: Bacen.

Banco Central do Brasil. (2002a). Circular Bacen $n^{\circ} 3.082$, de 30 de janeiro de 2002. Estabelece e consolida os critérios para registro e avaliação contábil de instrumentos financeiros derivativos. Brasília, DF: Bacen.

Banco Central do Brasil. (2002b). Circular Bacen $n^{\circ} 3.129$, de 27 de junho de 2002. Divulga procedimento relativo à instrução de processos por parte de instituições financeiras. Brasília, DF: Bacen.

Banco Central do Brasil. (2002c). Circular Bacen $n^{\circ}$ 3.150, de 11 de setembro de 2002. Estabelece critérios para registro e avaliação contábil de instrumentos financeiros derivativos, contratados de forma associada a operação de captação ou aplicação de recursos. Brasília, DF: Bacen. 
Banco Central do Brasil. (2006). Comunicado n. ${ }^{\circ} 14.259$, de 10 de março de 2006. Comunica procedimentos para a convergência das normas de contabilidade e auditoria aplicáveis às instituições financeiras e às demais instituições autorizadas a funcionar pelo Banco Central do Brasil com as normas internacionais promulgadas pelo International Accounting Standards Board (IASB) e pela International Federation of Accountants (IFAC). Brasília, DF: Bacen.

Banco Central do Brasil. (2007). Circular Bacen n³.354, de 27 de junho de 2007. Estabelece que a intenção de negociação precisa estar comprovada por meio de estratégias claramente documentadas e políticas e procedimentos de gestão ativas definidas. Brasília, DF: Bacen.

Banco Central do Brasil. (2008). Comunicado $n^{\circ}$ 16.669, de 20 de março de 2008. Comunica os procedimentos para a adequação das normas de contabilidade e auditoria aplicáveis às instituições financeiras e demais instituições autorizadas a funcionar pelo Banco Central do Brasil às disposições constantes da Lei $n^{\circ} 11.638$, de 31 de dezembro de 2007. Brasília, DF: Bacen.

Banco Central do Brasil. (2006). Relatório de Diagnóstico da Convergência às Normas Internacionais ao IAS 39. Brasília, DF: Departamento de Normas e Organização do Sistema Financeiro. https://www.bcb.gov.br/nor/convergencia/IAS_39_Instrumentos_Financeiros_Registro_de_Operacoes_de_Hedge.pdf

Banco Central do Brasil. Edital de Consulta Pública n 54, de 30 de agosto de 2017. https:// www.bcb.gov.br/htms/EditalConsultaPublica54.pdf

Barth, M. E., Landsman, W. R., \& Lang, M. H. (2007, September). International Accounting Standards and Accounting Quality. Research Papers Series, 1976, 1-52.

Bernhardt, T., Erlinger, D., \& Unterrainer, L. (2014). The new rules for hedge accounting from the risk management's perspective. ACRN Journal of Finance and Risk Perspectives, 3(3), 63-66. http://www.acrn-journals.eu/iframe-3/jofrp/jofrp0303.html

Capelletto, L. R., Oliveira, J. L., \& Carvalho, L. N. (2007). Aspectos do hedge accounting não implementados no Brasil. Revista de Administração da USP, 42(4), 511-523.

Campbell, J. L., Mauler, J. L., \& Pierce, S. R. (2019). A review of derivatives research in accounting and suggestions for future work. Journal of Accounting Literature, 42(2), 44-60.

Carmo, C. H. S., Ribeiro, A. M., \& Carvalho, L. N. G. (2011). Convergência de fato ou de direito? A influência do sistema jurídico na aceitação das normas internacionais para pequenas e médias empresas. Revista de Contabilidade \& Finanças, 22(57), 242-262. 
Ernst \& Young, \& Fipecafi. (2010). Manual de Normas Internacionais de Contabilidade: IFRS versus normas brasileiras. Atlas.

Feitosa, W. S. V. F., Galdi, F. C., \& Hartwig, A. (2020). A adoção de hedge accounting e a persistência dos resultados divulgados pelos bancos em atuação no mercado brasileiro. Contabilidade Vista \& Revista, 30(3), 106-127.

Financial Accounting Standards Board. (1998). Statement of financial accounting standards.

Gil, A. C. (2002). Como elaborar projetos de pesquisa (4a ed.). Atlas.

Ghasmi, H. M. (2016). Deliberative and comparative study of international financial reporting standards IFRS 9. International Journal of Science Research and Tecnology, 2(2), 23 32.

Glaum, M., \& Klöcker, A. (2011). Hedge Accounting and its influence on financial hedging: Evidence from Germany and Switzerland. Journal Accounting and Business Research, $41(5), 459-489$.

International Accounting Standards Board. (2003). Exposure draft of proposed amendments to IAS 39 financial instruments: Recognition and measurement fair value hedge accounting for a portfolio hedge of interest rate risk. http://appl.hkicpa.org.hk/professionaltechnical/accounting/rm/ed-ias39mh.pdf

International Financial Accounting Standards. (2017a). Financial Instruments. IAS 9. https:// www.iasplus.com/en-us/standards/international/ifrs-en-us/ifrs9

International Financial Accounting Standards. (2017b). Statement of cash flows. IAS 7. https://www.iasplus.com/en/standards/ias/ias7

KPMG. (2016). IFRS 9 - Instrumentos financeiros: Novas regras sobre a classificação e mensuração de ativos financeiros, incluindo a redução no valor recuperável. KPMG. https:// assets.kpmg.com/content/dam/kpmg/pdf/2016/04/ifrs-em-destaque-01-16.pdf

Lei n. ${ }^{\circ}$ 6.404. (1976, dezembro 17).

Lei n. ${ }^{\circ}$ 6.385. (1976, dezembro 7).

Lei n. ${ }^{\circ} 11.638$. (2007, dezembro 28).

Lei n. ${ }^{\circ}$ 11.941. (2009, maio 27). 
Marques, M. T., Dalmácio, F. Z., \& Rezende, A. J. (2020). IFRS vs BACEN GAAP: Accounting information's value relevance of the Brazilian financial institutions. Anais do USP International Conference Accounting, São Paulo, SP, Brasil, 20.

Niyama, J. K., Costa, P. S., \& Aquino, D. R. B. (2005). Principais causas das diferenças internacionais no financial reporting: Uma pesquisa empírica em instituições de ensino superior do nordeste e centro-oeste do Brasil. Contexto, 5(8), 1-15.

Oliveira, J. L. (2003). A aplicação e a divulgação do hedge accounting nas demonstrações contábeis de bancos brasileiros em 2002. Dissertação de Mestrado, Universidade de Brasília, DF, Brasil.

Pierce, S. (2020). Determinants and consequences of firms' derivative accounting decisions. Journal of Financial Reporting. https://papers.ssrn.com/sol3/Papers.cfm?abstract_ $\mathrm{id}=2685896$

Price Waterhouse Coopers Brasil. (2017). IFRS 9 O tempo está esgotando: Analisando as implicações da nova norma sobre instituições financeiras. https://www.pwc.com.br/pt/estudos/servicos/auditoria/2017/f220_ifrs9_17.pdf

Santos, E. S., Cia, J. N. S., \& Cia, J. C. (2011). US GAAP x Normas Brasileiras: Mensuração do impacto das diferenças de normas no lucro duplamente reportado pelas empresas brasileiras emissoras de ADRs na NYSE. Revista de Administração Mackenzie, 12(1), 82-111.

Saito, S., \& Fukui, Y. (2016). Hedging and hedge accounting in a multiperiod world: A cash flow-centered view. SSRN, Working Paper. https://papers.ssrn.com/sol3/papers.cfm?abstract_id $=2710985$

Singh, J.P. (2017). Hedge Accounting under IFRS 9: An analysis of reforms. Audit Financiar, 15(145), 103-113. 